OPEN ACCESS

Edited by:

Xiaodong Sun,

Affiliated Hospital of Weifang Medical

University, China

Reviewed by:

Tianpeng Zheng,

Guilin Medical University, China

Xuan Li,

University of Mississippi Medical

Center, United States

*Correspondence:

Yunxia Liu

yunxial19@mails.jlu.edu.cn

Yang Zheng

zhengyang@ilu.edu.cn

Specialty section: This article was submitted to

Cellular Endocrinology,

a section of the journal

Frontiers in Endocrinology

Received: 17 May 2021

Accepted: 21 July 2021

Published: 11 August 2021

Citation:

Chen Y, Qin Z, Wang Y, Li X

Zheng $Y$ and Liu $Y$ (2021) Role

of Inflammation in Vascular

Disease-Related Perivascular

Adipose Tissue Dysfunction.

Front. Endocrinol. 12:710842. doi: 10.3389/fendo.2021.710842

\section{Role of Inflammation in Vascular Disease-Related Perivascular Adipose Tissue Dysfunction}

\author{
Yaozhi Chen ${ }^{1}$, Zeyu Qin ${ }^{2}$, Yaqiong Wang ${ }^{3}$, Xin Li $^{1}$, Yang Zheng ${ }^{1 *}$ and Yunxia Liu ${ }^{1 *}$ \\ ${ }_{1}$ Center for Cardiovascular Medicine, First Hospital of Jilin University, Changchun, China, ${ }^{2}$ Department of Respiratory \\ Medicine, First Hospital of Jilin University, Changchun, China, ${ }^{3}$ Department of Endocrinology and Metabolism, First Hospital \\ of Jilin University, Changchun, China
}

Perivascular adipose tissue (PVAT) is the connective tissue around most blood vessels throughout the body. It provides mechanical support and maintains vascular homeostasis in a paracrine/endocrine manner. Under physiological conditions, PVAT has antiinflammatory effects, improves free fatty acid metabolism, and regulates vasodilation. In pathological conditions, PVAT is dysfunctional, secretes many anti-vasodilator factors, and participates in vascular inflammation through various cells and mediators; thus, it causes dysfunction involving vascular smooth muscle cells and endothelial cells. Inflammation is an important pathophysiological event in many vascular diseases, such as vascular aging, atherosclerosis, and hypertension. Therefore, the pro-inflammatory crosstalk between PVAT and blood vessels may comprise a novel therapeutic target for the prevention and treatment of vascular diseases. In this review, we summarize findings concerning PVAT function and inflammation in different pathophysiological backgrounds, focusing on the secretory functions of PVAT and the crosstalk between PVAT and vascular inflammation in terms of vascular aging, atherosclerosis, hypertension, diabetes mellitus, and other diseases. We also discuss anti-inflammatory treatment for potential vascular diseases involving PVAT.

Keywords: perivascular adipose tissue, vascular diseases, inflammation, endocrine, crosstalk

\section{INTRODUCTION}

The vascular system is a highly branched network lined with endothelial cells (ECs) and vascular smooth muscle cells (VSMCs), which can provide oxygen and nutrition for tissues. The regulation of vascular function in response to changing metabolic needs is essential for the maintenance of normal tissue and organ functions; it is also important for health preservation and disease prevention (1). Vascular diseases caused by vascular injury and dysfunction are among the top five causes of death among non-communicable diseases worldwide; these diseases influence various other diseases, such as heart diseases, nervous system diseases, and metabolic disorders (2). Vascular homeostasis is regulated by many factors, among which perivascular adipose tissue (PVAT) plays an important role in the pathogenesis of vascular diseases.

PVAT, which surrounds most blood vessels (except cerebral vessels) (3), is a connective tissue composed of adipocytes, preadipocytes, mesenchymal stem cells, fibroblasts, inflammatory cells 
(macrophages, lymphocytes, and eosinophils), vascular cells, and nerves; these cells form adipose tissue microvasculature (4). PVAT is characterized by a reduced degree of differentiation, compared with classical visceral fat (PVAT more closely resembles preadipocytes); moreover, it exhibits a tendency to release proinflammatory factors and growth factors (5). Because of the anatomical characteristics of its adjacent vessel walls, PVAT provides mechanical support in the vascular system, particularly during adjacent tissue contraction. Furthermore, PVAT releases various factors, including adipokines and cytokines/chemokines. Through paracrine/endocrine mechanisms, these factors can directly diffuse or reach the vascular endothelial layer through blood vessels or a network of small mediators that connects the middle layer and lower adventitia. Additionally, these factors regulate vascular tension, cell proliferation, and cell migration; exhibit considerable influence on vascular homeostasis and function; and demonstrate both protective and harmful effects on the vascular system, according to pathophysiological characteristics present in the tissue microenvironment.

Under physiological conditions, PVAT has anti-inflammatory effects, improves free fatty acid metabolism, and regulates vasodilation. However, in the event of vascular pathology, PVAT increases in volume and becomes dysfunctional. This leads to changes in cell composition and molecular characteristics, as well as extensive secretion of pro-inflammatory and anti-vasodilation factors; it also promotes the infiltration of inflammatory immune cells and local oxidative stress, triggering vascular wall "from the outside to the inside" pathological signal, thereby causing VSMC and EC dysfunction $(6,7)$. The specific mechanisms and characteristics of PVAT dysfunction may differ among vascular diseases, despite important similarities with respect to inflammation characteristics. Inflammation is also an important pathophysiological event in vascular aging, atherosclerosis, hypertension, diabetes mellitus (DM), and other vascular diseases $(8,9)$. Therefore, the proinflammatory crosstalk between PVAT and blood vessels may comprise a novel therapeutic target for the prevention and treatment of vascular diseases. In this review, we summarize the latest findings regarding PVAT function and inflammation in various pathophysiological contexts and discuss anti-inflammatory treatments for potential PVAT-related vascular diseases.

\section{SECRETORY FUNCTIONS OF PVAT}

PVAT is considered an important endocrine tissue for the maintenance of intravascular stability. Although most inflammation in PVAT is attributed to infiltration by macrophages and T cells, PVAT-related regulation of vascular function depends largely on its secretory functions (Figure 1). Dysfunctional adipocytes themselves exhibit pro-inflammatory phenotypes and may play important roles in triggering and spreading inflammation within PVAT (10). Similar to other adipose tissues, PVAT secretes many adipose tissue-specific adipokines, chemokines, and growth factors; these directly affect the functions of adjacent blood vessels in a paracrine manner and can also reach the lumens of adjacent blood vessels, then have various downstream effects. PVAT affects tension and endothelial functions throughout the vascular bed in a vascular secretion manner, thus triggering and coordinating the infiltration of inflammatory cells (e.g., T cells, macrophages, dendritic cells, B cells, and NK cells) (11).

Under physiological conditions, PVAT mainly secretes antiinflammatory adipokines, such as adiponectin (APN), omentin, fibroblast growth factor-21 (FGF-21), and nitric oxide (NO) (Figure 1A). In the context of vascular dysfunction, PVAT mostly produces and releases pro-inflammatory adipokines, such as leptin, tumor necrosis factor- $\alpha$ (TNF- $\alpha$ ), monocyte chemoattractant protein-1 (MCP-1, also known as CCL2), RANTES (Chemokine C-C motif ligand 5, CCL5), interleukin6 (IL-6), and interleukin-1 $\beta$ (IL-1 $\beta$ ); all of these factors can directly affect VSMCs and ECs, thus triggering and coordinating vascular inflammation (Figure 1B) $(5,9)$.

\section{PVAT and Anti-Inflammatory Cytokines}

Under physiological conditions, PVAT releases various antiinflammatory factors, including APN. The main biological
A

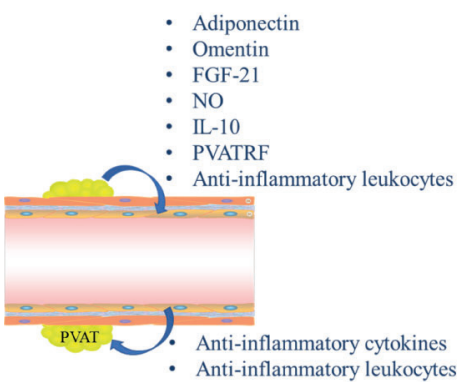

B

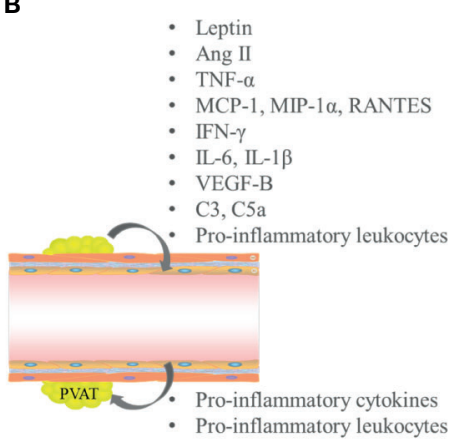

FIGURE 1 | Secretory functions mediate inflammatory crosstalk between perivascular adipose tissue (PVAT) and blood vessels. (A) Interactions between PVAT and blood vessels in normal physiological conditions. (B) Crosstalk between PVAT and blood vessels in pathological conditions. FGF-21, fibroblast growth factor-21; NO, nitric oxide; IL, interleukin; PVATRF, PVAT-derived relaxing factor; TGF- $\beta 1$, transforming growth factor- $\beta 1$; Ang II, angiotensin II; TNF- $\alpha$, tumor necrosis factor- $\alpha$; MCP-1, monocyte chemoattractant protein-1; MIP-1 $\alpha$, macrophage inflammatory protein $1 \alpha$; IFN- $\gamma$, interferon $\gamma$; VEGF-B, vascular endothelial growth factor B. 
functions of APN include promotion of fatty acid biosynthesis and inhibition of gluconeogenesis in liver, enhancement of glucose uptake in skeletal muscle, improvement of systemic insulin resistance, and prevention of systemic atherosclerosis by increasing fatty acid oxidation (12).

The effects of APN-mediated anti-inflammatory action on vascular function have been elucidated in multiple vascular diseases. Compared with mice that were fed a regular chow diet, the anti-contractile effect of PVAT was significantly reduced in non-endothelial aortic rings in mice that were fed a high-fat diet, partly because of reduced APN release from PVAT, associated with AMPK dysfunction and/or PVAT inflammation (13-16). APN expression is reportedly downregulated in desoxycorticosterone acetate (DOCA)-salt hypertensive mice because of complement activation in PVAT; this effect can be reversed by macrophage depletion (17). Transplanted PVAT exhibits reduced expression of APN, thereby aggravating endothelial dysfunction through an inflammatory response (18). Exogenous APN can restore aortic anti-contractile activity of adult male offspring in mice exposed to gestational intermittent hypoxia (19). Upregulation of the heme oxygenase-1/APN axis in PVAT mediates anti-contractility-related Irisin improvement in the thoracic aorta of obese mice $(15,20)$. Chronic APN therapy can inhibit chemokine and pro-inflammatory adipokine expression patterns in PVAT in both aged rats and rats that were fed a high-fat diet, thus improving endothelial dysfunction in these models (21). PVAT around the coronary artery, collectively classified as epicardial adipose tissue (EAT), is closely related to the occurrence and development of coronary atherosclerotic lesions, as well as plaque stability. Angiotensin converting enzyme 2 (ACE2)-knockout mice that were fed a high-fat diet exhibited increased EAT inflammation; this was associated with decreased cardiac APN, decreased AMPK phosphorylation, increased cardiac steatosis and lipotoxicity, and myocardial insulin resistance, which exacerbated cardiac functional damage (22). In EAT from patients with coronary heart disease (CHD), the levels of APN decreased, while the levels of IL-6, TNF- $\alpha$, and Toll-like receptor 4 increased. APN administration has been shown to prevent atherosclerosis by reducing the production of TNF- $\alpha$ in macrophages and reactive oxygen species (ROS) in endothelial cells; it also increases endothelial cell migration and angiogenesis (23). Samples from humans indicate that type 2 diabetes (T2DM) is closely related to hypoadiponectin, suggesting that the APN signaling pathway can serve as a new route for vascular protection in blood vessels and PVAT. However, the molecular mechanism by which APN reduces vascular inflammation remains unclear. Inhibition of nuclear factor kappa-B (NF- $\mathrm{KB}$ ) signaling (which regulates several pro-inflammatory genes) and its transcription factors may be another mechanism by which APN alleviates vascular dysfunction (24).

Omentin (also known as intelectin-1, lactoferrin receptor, or endothelial lectin) has a positive effect on vascular inflammation. By inhibiting the thioredoxin-interacting protein/nucleotidebinding oligomerization domain-like receptor family pyrin domain-containing 3 signaling pathway, omentin can reduce the production of pro-inflammatory cytokines (e.g., TNF- $\alpha$, IL-6, and IL-1 $\beta$ ) and increase the production of anti-inflammatory cytokines (e.g., APN and IL-10) in obese mouse adipose tissue, as well as macrophages co-cultured with lipopolysaccharides (25, 26). The anti-contractile effect of PVAT in a physiological environment was lost in patients with T2DM, although it partially recovered after treatment with omentin-1, the main cyclic forms of omentin (27). Furthermore, omentin-1 treatment significantly improved the pro-inflammatory and pro-oxidant PVAT phenotype (i.e., through reduction of C-reactive protein and nitrotyrosine levels), suggesting that omentin-1 could improve endothelial dysfunction in T2DM patients by improving dysfunction PVAT; it also has the potential to treat T2DMrelated vascular complications (28). In patients with atrial fibrillation and valvular heart diseases, the expression of omentin was downregulated in EAT and right atrial appendage tissue (29). Importantly, the expression of omentin in EAT was lower in patients with $\mathrm{CHD}$ than in patients without $\mathrm{CHD}$; the expression of omentin in EAT was lower around stenotic segments of coronary artery than around non-stenotic segments (30). However, another study showed that, compared with the control group, the expression of omentin in EAT increased in patients with $\mathrm{CHD}$, despite reduction of its circulating level; this finding suggested that omentin may play a local role in the development of CHD (31).

FGF-21, a member of the fibroblast growth factor family, is an important endocrine regulator that mainly acts through induction of weight loss and management of insulin signaling, as well as management of glucose and lipid metabolism (32). It also has important anti-inflammatory roles in various tissues/ cells, such as obese adipose tissue, cardiac tissue, and macrophages (33-37). FGF-21 gene expression was reportedly reduced in EAT from patients with multivessel $\mathrm{CHD}$ associated with T2DM (38), while FGF-21 expression was enhanced in EAT from patients undergoing cardiac surgery, suggesting that FGF21 has a protective effect against cardiac surgery-related inflammation (39). Therefore, anti-inflammatory pathways related to PVAT may comprise novel targets for the prevention and treatment of various vascular diseases.

\section{PVAT and Pro-Inflammatory Cytokines}

Leptin is another rich adipokine released by adipose tissue (including PVAT), which was the first adipokine reported in the literature. Under physiological conditions, leptin mainly relies on hypothalamus and sympathetic nerve signaling to reduce appetite, increase energy consumption, and regulate glucose homeostasis, independent of insulin (40). Leptin resistance is associated with the development of hypertension and insulin resistance (40), and inflammation is an important contributor to leptin resistance (41). Classically, leptin is regarded as a pro-inflammatory cytokine, which has structural homology with other cytokines such as TNF- $\alpha$ and IL-6 $(41,42)$. Leptin plays a direct role in inflammation by inducing monocytes, leukocytes, and macrophages to produce IL-6, TNF- $\alpha$, and IL-12; thus, it increases the production and migration of ROS in monocytes, as well as the production of chemokine ligands by macrophages $(42,43)$. 
In obese sedentary mice, PVAT ring-deficient mice exhibited lower levels of circulating glucose, insulin, resistin, leptin, and TNF- $\alpha$; they also demonstrated abnormal endothelial function in thoracic aorta (44). The reduction of leptin expression in PVAT may inhibit neointimal hyperplasia and vascular remodeling by inhibiting monocyte migration and VSMC proliferation (45). Gene expression profiling showed that the expression levels of IL-1 $\beta$, IL-6, and leptin in patients with CHD were significantly higher in PVAT around the coronary artery than in PVAT inside the thoracic artery (46). In addition, data from patients undergoing coronary artery bypass grafting indicated that the leptin-inflammation-fibrosis-hypoxia axis plays a key role in coronary atherosclerosis pathogenesis. Compared with PVAT surrounding the anti-atherosclerotic internal mammary artery, leptin expression was significantly increased in "cardiac" PVAT surrounding the aortic root and coronary arteries (C-PVAT). This increased expression was accompanied by more obvious angiogenesis and inflammation, indicating significant increases in the numbers of platelets, endothelial cell adhesion molecule 1-positive vessels, and CD68-positive macrophages, as well as greater degrees of fibrosis and hypoxia, which may lead to an enhanced coronary atherosclerotic plaque load (47). Increased expression levels of hypoxia inducible factor- $1 \alpha$ and Fos-like antigen 2 were observed in C-PVAT; these factors reportedly enhance leptin gene transcription (47). The findings thus far suggest that PVAT plays an important role in promoting vascular inflammation through leptin secretion.

Notably, adipocytes and macrophages in PVAT also secrete large amounts of TNF- $\alpha$; these levels are higher in obese animals and people than in lean animals and lean people. TNF- $\alpha$ induces aortic intima-media thickening through PVAT inflammation (48). TNF- $\alpha$ has pro-inflammatory effects and can promote the production of other pro-inflammatory factors (e.g., IL-6, leptin, and resistin). Furthermore, MCP-1 produced by adipocytes has been identified as a potential factor for macrophage infiltration into adipose tissue $(49,50)$. The increased expression levels of MCP-1 and TNF- $\alpha$ in transplanted PVAT tissue can aggravate endothelial dysfunction and atherosclerosis in distant vessels by enhancing the inflammatory response (18). In addition, RANTES (produced by $\mathrm{T}$ cells, macrophages, VSMCs, ECs, and PVAT adipocytes (51-53)) is a key factor for leukocyte recruitment to sites of inflammation or infection (54). Increased RANTES expression levels in hypertensive PVAT induce T-cell chemotaxis and vascular accumulation of $\mathrm{T}$ cells that express RANTES receptors (55). In addition, PVAT secretes free fatty acids, resistin, visfatin, and other pro-inflammatory adipokines, which participate in the occurrence and development of vascular diseases (56-58).

\section{ROLES OF PVAT IN VASCULAR DISEASE}

Morphological, structural, and functional changes of PVAT have been investigated in major vascular lesions associated with vascular diseases such as vascular aging, atherosclerosis, hypertension, and DM-related vascular dysfunction (Table 1).

\section{Vascular Aging}

Aging is an independent risk factor for vascular diseases. Vascular aging is mainly characterized by blood vessel-related structural changes and dysfunction that increase with age, which culminate in age-related vascular diseases (112-114). In such diseases, the vascular wall exhibits a pro-inflammatory microenvironment associated with low-grade perivascular inflammation, which is characterized by increased secretion of pro-inflammatory cytokines and chemokines, as well as enhanced infiltration of immune cells (4). These changes promote vascular dysfunction, hinder cell metabolism, increase cell apoptosis, and contribute to the onset of vascular diseases (115). In this context, PVAT is a key factor that affects vascular and perivascular inflammation during aging (Table 1).

There is increasing evidence that age can affect PVAT morphology and function, increase PVAT-related inflammation, and affect the corresponding vascular activity. In rats, aging reportedly attenuated the anti-contractile effect of PVAT around the thoracic aorta, while reducing the amount of brown adipose tissue-like PVAT (59). In the mesenteric arteries of SHRSP.Z-Leprfa/IzmDmcr rats (SHRSP.ZF) with metabolic syndrome, vascular dysfunction is compensated by a PVATdependent mechanism, which disappears with age (60). Compared with young C57BL/6JRj mice, middle-aged mice showed more PVAT hypertrophy (61); furthermore, the mean single adipocyte area in PVAT was significantly increased, while the expression level of protein inhibitor of activated signal transducer and activators of transcription 1 (a key negative regulator of inflammation) was decreased. These effects may contribute to age-related vascular diseases (61).

With increasing age, resident stromal cells in PVAT (PVASCs) exhibit decreasing differentiation ability, which contributes to neointimal hyperplasia and vascular remodeling after PVAT transplantation into carotid artery. This may be caused by the loss of PGC1 $\alpha$ in aged PVASCs, which can be improved by overexpression of PGC1 $\alpha$ (62). Senescenceaccelerated prone mice (SAMP8), a mouse model of aging, shows vascular dysfunction associated with hypertension and cognitive decline (116). Compared with control senescenceaccelerated resistant mice (SAMR1), aged SAMP8 mice reportedly demonstrated the lack of an anti-vasoconstrictive effect of PVAT; they also exhibited increased tunica media thickness, decreased APN expression, and enhanced expression levels of vascular markers of inflammation (e.g., endothelin-1, inducible nitric oxide synthase, and cyclooxygenase 2) (63).

Arterial stiffness is an inevitable result of aging. Local PVAT homeostasis, especially inflammation in PVAT, is associated with the development of age-related arterial stiffness. Loss of functional PVAT can enhance arterial stiffness in aging mice; furthermore, aged C57BL/6J mice that were fed a high-fat diet demonstrated significant induction of PVAT hypertrophy and enhancement of arterial stiffness. This change is related to the low level of mitoNEET expression in PVAT, which increases the expression of pro-inflammatory genes (64). In addition, older arteries are more susceptible to obesity-induced aging, compared with younger arteries (65). Aging aggravates obesity-induced 
TABLE 1 | Central roles of PVAT inflammation in vascular diseases.

\begin{tabular}{|c|c|c|c|}
\hline & Vessels & PVAT & Reference \\
\hline Vascular aging & $\begin{array}{l}\text { - Increased tunica media thickness } \\
\text { - } \quad \text { Increased oxidative stress and inflammation } \\
\text { (ET-1, iNOS, COX2) } \\
\text { - } \quad \text { VSMCs proliferation } \\
\text { - } \quad \text { Increased perivascular fibrosis } \\
\text { - } \quad \text { Increased arterial stiffness }\end{array}$ & $\begin{array}{l}\text { - PVAT was hypertrophic and the average area of } \\
\text { single adipocyte was significantly increased } \\
\text { - The differentiation ability of PVASCs decreased } \\
\text { - Increased proinflammatory mediators (TNF- } \alpha, \quad \mathrm{L}-6 \text {, } \\
\text { eotaxin, MIP-1 } \alpha, \mathrm{MCP}-1 \text { and RANTES) } \\
\text { - } \quad \text { Reduction of ant-inflammatory mediators (APN) } \\
\text { - The function of anti- vasoconstriction is weakened } \\
\text { - The infiltration of macrophages and natural killer cells }\end{array}$ & $(59-68)$ \\
\hline Atherosclerosis & $\begin{array}{l}\text { The infiltration of macrophages, T cells and dendritic } \\
\text { cells increased } \\
\text { - Plaque volume increased, internal lipid increased, } \\
\text { high macrophage density and fibrin deposition } \\
\text { - Increased proinflammatory mediators } \\
\text { - Increased perivascular inflammation }\end{array}$ & $\begin{array}{l}\text { - The size of adipocytes was smaller and the } \\
\text { differentiation phenotype was less } \\
\text { Increased proinflammatory mediators (TNF- } \alpha \text {, IL-6, } \\
\text { IL-1 } \beta \text {, MCP-1, resistin, and osteoprotegerin) } \\
\text { - } \quad \text { Reduction of ant-inflammatory mediators (APN) } \\
\text { - The infiltration of macrophages, T cells and dendritic } \\
\text { cells increased } \\
\text { B-1 cells and their secretion of anti-atherosclerotic } \\
\text { IgM decrease }\end{array}$ & $\begin{array}{c}(10,18,69-77) \\
(67,78-86)\end{array}$ \\
\hline Hypertension & $\begin{array}{ll}\text { - } & \text { Increased proinflammatory mediators (MCP-1, } \\
\text { - } & \text { RANTES and MIP-1 } \alpha \text { ) } \\
\text { - } & \text { Increased vascular tone } \\
\text { - } & \text { Systolic and diastolic blood pressure increased } \\
\text { - } & \text { vascular hypertrophy and fibrosis } \\
\text { - } & \text { Increased perivascular inflammation }\end{array}$ & $\begin{array}{l}\text { - The function of anti- vasoconstriction is weakened } \\
\text { - } \quad \text { Decreased production of vasodilator factor } \\
\text { - Increased angiotensin II secretion } \\
\text { - Increased proinflammatory mediators (IFN- } \gamma, \\
\text { - RANTES, C3, C5a, MCP-1, TNF- } \alpha, \text { IL-6, MIP-1 } \alpha \text { ) } \\
\text { - } \quad \text { Reduction of ant-inflammatory mediators (APN) } \\
\text { - The infiltration of macrophages, T cells and dendritic } \\
\text { - The number of eosinophils decreased }\end{array}$ & $\begin{array}{c}(17,55,68,72, \\
87-97)\end{array}$ \\
\hline $\begin{array}{l}\text { Diabetes mellitus related } \\
\text { vascular dysfunction }\end{array}$ & $\begin{array}{l}\text { - Increased insulin resistance } \\
\text { - Impaired vasodilation and vascular remodeling } \\
\text { mediated by insulin } \\
\text { - The adhesion ability of endothelial cells to } \\
\text { lymphocytes increased }\end{array}$ & $\begin{array}{l}\text { PVAT phenotype changed to pro-inflammatory, pro } \\
\text { oxidative and pro vasoconstrictive state } \\
\text { Increased infiltration of M1 macrophages and } \\
\text { dendritic cells } \\
\text { - Overproduction of proinflammatory cytokines(IFN- } \gamma \text {, } \\
\text { TNF- } \alpha \text {, and IL-6) } \\
\text { Reduction of anti-inflammatory cytokines (IL-10 and } \\
\text { APN) }\end{array}$ & $(98-102)$ \\
\hline $\begin{array}{l}\text { Abdominal aortic } \\
\text { aneurysm }\end{array}$ & $\begin{array}{l}\text { Recruitment of inflammatory cells (macrophages, } \\
\text { lymphocytes, and mast cells) in vascular wall } \\
\text { Increased expression of perivascular inflammatory } \\
\text { factors } \\
\text { - Enhanced leukocyte- fibroblast interaction in } \\
\text { adventitia } \\
\text { Migration and proliferation of adventitial fibroblasts } \\
\text { increased }\end{array}$ & $\begin{array}{l}\text { - Increased PVAT deposition } \\
\text { - Co-localization of PVAT inflammation and abdominal } \\
\text { aortic aneurysm } \\
\text { - Increased gene expression of proinflammatory factors } \\
\text { (IL-8, PTPRC, LCK, and CCL5) } \\
\text { - Decreased expression of anti-inflammatory PPAR } \gamma\end{array}$ & $(103-111)$ \\
\hline
\end{tabular}

The table lists changes in PVAT and vascular inflammation during the onset of vascular aging, atherosclerosis, hypertension, diabetes mellitus-related vascular dysfunction and abdominal aortic aneurysm (note that the anti-atherosclerotic effects of healthy PVAT are not listed). ET-1, endothelin-1; iNOS, inducible nitric oxide synthase; COX2, cyclooxygenase 2; VSMCs, vascular smooth muscle cells; PVASCs, resident stromal cells in PVAT; APN, adiponectin; PTPRC, protein tyrosine phosphatase receptor type C; LCK, lymphocyte-specific protein tyrosine kinase; PPAR $\gamma$, peroxisome proliferator-activated receptor gamma.

PVAT inflammation, promotes secretion of pro-inflammatory factors by PVAT (including cytokines such as TNF $\alpha$ and IL-6, as well as chemokines such as eotaxin and MIP-1 $\alpha$ ), and reduces APN secretion, thus increasing vascular oxidative stress and inflammation in a paracrine manner, and stimulating VSMC proliferation $(65,66)$.

The effect of PVAT on vascular senescence depends on its secretion, as well as the presence of inflammatory cells. Studies in humans have shown that age and body mass index are associated with the density of CD68-positive macrophages in PVAT (67). In spontaneously hypertensive rats, aging is associated with increased numbers of infiltrating leukocytes, macrophages, and natural killer cells in PVAT, accompanied by gradual elevation of blood pressure. Dual pharmacological inhibition of Nox1 and
NOX4 increases blood pressure and leads to the accumulation of immune cells in PVAT. These effects are related to increased expression levels of MCP-1 and RANTES in PVAT, which lead to enhancement of perivascular fibrosis and acceleration of vascular aging (68). Overall, the existing evidence shows that PVAT mediates changes associated with vascular aging by enhancing infiltration of multiple inflammatory cells and release of various pro-inflammatory factors.

\section{Atherosclerosis}

Vascular diseases (e.g., myocardial infarction and cerebral infarction) are often caused by atherosclerosis, a vascular disease with robust inflammation, which is characterized by the accumulation of lipids, diseased cells, and necrotic debris. 
Proinflammatory leukocytes and cytokines play important roles in various stages of atherosclerotic plaque formation (117). There is increasing evidence that perivascular inflammation contributes to multiple stages of atherosclerosis; notably, PVAT plays an important role in triggering adventitial inflammation in atherosclerosis. Furthermore, PVAT promotes atherosclerosis in basic vessels through "from the outside to the inside" signal transduction. However, PVAT exhibits a nonuniform role in the development of atherosclerosis. PVAT may have dual effects (i.e., both pro- and anti-atherosclerosis), which may influence balance in the local environment.

Healthy PVAT plays a protective role in regulating metabolism, inflammation, and function in nearby blood vessels. Healthy PVAT may contain immune cells that impede the development of atherosclerosis (118). The absence of PVAT can lead to enhanced macrophage infiltration and increased pro-inflammatory cytokine production in the aortic perivascular area, thus exacerbating vascular inflammation and atherosclerotic lesions in aortic wall tissue (119). In addition, PVAT is the main source of aortaassociated B lymphocytes. Many of these B cells belong to the anti-atherosclerotic B-1 subgroup; IgM secreted by this subgroup of $B$ cells can reduce the effects of pro-inflammatory cytokines produced by M1 macrophages. Notably, the ratio of B-1/B-2 cells is reportedly 10-fold higher in PVAT than in spleen or bone marrow, indicating an important anti-inflammatory effect of PVAT (120).

The number of B-1 cells secreting anti-atherosclerotic IgM is reportedly reduced in PVAT from apolipoprotein E-/- (ApoE-/-) mice, which significantly aggravates atherosclerosis in the aorta and coronary artery (69). A systemic endocrine mechanism also mediates the anti-atherosclerotic effect of PVAT. The transplantation of PVAT from thoracic aorta of wild mice was able to reduce the atherosclerotic plaque size in suprarenal aorta of ApoE-/- mice that were fed a high-cholesterol diet. This antiatherosclerotic effect was mediated by a transforming growth factor- $\beta 1$-induced anti-inflammatory response, which may involve alternatively activated macrophages (121). In addition, APN derived from PVAT can inhibit carotid collar-induced carotid atherosclerosis by promoting macrophage autophagy (122).

In the context of chronic hyperthermia, PVAT dysfunction exacerbates atherosclerosis and increases the risk of plaque rupture. In dysfunctional PVAT, the secretion of anti-inflammatory factors (e.g., APN) is decreased, while the secretion of pro-inflammatory cytokines is increased; thus, the distribution of pro-inflammatory and anti-inflammatory immune cells is unbalanced. These changes lead to the enhancement of local inflammation, aggravating the development of atherosclerosis (Table 1).

Pathological conditions (such as altered expression of angiotensin II [Ang II] or pro-atherosclerotic factors) increase the dedifferentiation of PVAT adipocytes $(70,71)$. In larger vessels associated with atherosclerosis, adipocytes in PVAT are usually smaller and exhibit a less differentiated phenotype (10, $72,73)$. Inflammation in PVAT and adventitia occurs prior to endothelial dysfunction and atherosclerotic plaque formation (74). In human aorta, PVAT accumulates in sites where atherosclerosis can easily form, while inflammatory cells concentrate in PVAT at the edge of adventitia and secrete chemokines that can attract monocytes and $\mathrm{T}$ cells to the adventitial interface, suggesting that PVAT promotes vascular inflammation (75). Compared with non-diseased aorta, inflammatory cells exhibited significantly increased infiltration in PVAT around atherosclerotic aorta (123). During the onset of atherosclerosis in ApoE-/- mice, macrophages, T cells, and dendritic cells were recruited into the adventitia and PVAT $(75,76)$, in a manner influenced by age (75). In addition, compared with subcutaneous adipose tissue transplantation in mice, carotid artery transplantation of PVAT reportedly causes large lipid rich atherosclerotic lesions in thoracic aorta, as well as high macrophage density and fibrin deposition. The inhibition of leukocyte ligand P-selectin glycoprotein ligand 1 may provide a therapeutic method to reduce the effects of PVAT inflammation on atherosclerosis (77). PVAT expansion and inflammation in obesity can remotely induce endothelial dysfunction and aggravate atherosclerosis. Transplantation of PVAT from the abdominal aorta of mice that were fed a high-fat diet promoted inflammation (increased expression of TNF- $\alpha$ and MCP-1; decreased expression of APN), endothelial dysfunction, and atherosclerosis in thoracic aorta, suggesting that enhanced inflammation is the potential mechanism by which PVAT exhibits a distal vascular effect (18).

Data from human samples showed that the densities of $B$ lymphocytes and macrophages in PVAT around atherosclerotic plaque increased with plaque size; the corresponding inflammation increased with increasing coronary artery occlusion (67). The number of macrophages in PVAT was also associated with the number of immune cells in plaque (78-80). In addition, the density of macrophages was higher in PVAT near unstable plaque than in PVAT near the stable plaque. The inflammation was stronger in PVAT near stenotic sites and acute lesions than in adipose tissue distant from lesions, in the absence of atherosclerosis (67).

Pro-atherosclerotic mediators derived from dysfunctional PVAT may comprise another mechanism underlying human vascular atherosclerosis (81). Analysis of dysfunctional PVAT has revealed upregulated expression of pro-inflammatory genes, as well as downregulated expression of anti-inflammatory adiponectin (82-84). EAT from patients undergoing coronary artery bypass grafting showed significantly higher levels of chemokines (MCP-1) and pro-inflammatory cytokines (IL- $1 \beta$, IL- 6 , and TNF- $\alpha$ ), compared with levels in subcutaneous adipose tissue from the same patients (84). Furthermore, the expression of antiinflammatory APN was significantly lower in EAT samples from patients with severe coronary atherosclerosis than in EAT samples from patients without coronary atherosclerosis (83), suggesting an inflammation imbalance in PVAT from patients with atherosclerosis. The colocalization of macrophages and resistin (an adipokine that can enhance endothelial cell permeability in vitro) in human PVAT indicates that PVAT may participate in the pathogenesis of atherosclerosis through various mechanisms $(82,85)$. Osteoprotegerin, a member of the TNF-related family, is associated with atherosclerotic progression and increased instability; its expression is strongly upregulated in human perivascular adipocytes (124). 
Importantly, vascular wall-associated inflammation also affects the dynamic balance of PVAT. In the presence of coronary artery inflammation and atherosclerosis, the release of pro-inflammatory mediators from the vascular wall to the surrounding PVAT leads to altered adipocyte differentiation and intracellular lipid formation, which greatly influences cardiovascular diagnosis and contributes to distinctive imaging findings (86). Noninvasive detection of PVAT can provide structural information and distinguish unstable atherosclerotic lesions. In postmortem studies of human patients, atherosclerotic plaque size and complex lipid core composition were positively associated with PVAT volume and macrophage infiltration (79). Because PVAT inflammation is related to disordered adipocyte differentiation and reduced lipid content in adipocytes, Antonopoulos et al. examined the perivascular CT fat attenuation index (FAI), a water to fat ratio index with good sensitivity and specificity in the differential diagnosis of PVAT inflammation (86). Importantly, they found that the perivascular FAI was greater in unstable plaque than in stable plaque; it was greatest near inflamed coronary arteries. PVAT imaging can provide spatial location information regarding the human coronary arteritis microenvironment, which enables early identification of high-risk plaques and may facilitate further treatment.

\section{Hypertension}

Inflammation is an important factor involved in hypertension, which involves high blood pressure and can cause both end organ damage and dysfunction $(125,126)$. The main site of initial inflammation in hypertension is reportedly within PVAT and the PVAT/adventitia boundary $(55,127)$. Inflammation leads to the loss of the anti-contractile effect of PVAT, potentially because of adipose tissue dysfunction (128). The production of vasodilators derived from PVAT adipocytes decreases during inflammation, while pro-inflammatory adipokines increasingly infiltrate into the adjacent vascular system (5); these changes enhance vascular inflammation and vascular resistance (68). PVAT inflammation leads to vascular dysfunction in the context of hypertension. Various inflammatory cells participate in this process, which is mediated by a series of cytokines and chemokines; for example, interferon- $\gamma$ is produced by CD8+ cells infiltrating PVAT $(55,87)$, RANTES mediates the infiltration of $\mathrm{T}$ cells into perivascular space (55), and complement C5a mediates decreased APN production (17). These inflammation-related changes exacerbate the proinflammatory crosstalk and dysfunction between PVAT and hypertensive vessels (Table 1).

The infiltration and activation of macrophages dispersed in PVAT are important contributing factors in hypertension-related inflammation. The expression of complement C3 is reportedly increased in PVAT from DOCA-salt hypertensive mice (88), resulting in increased expression of pro-inflammatory M1 macrophage phenotype markers and decreased expression of anti-inflammatory M2 macrophage phenotype markers. Bone marrow-specific C3 deficiency significantly improved DOCAsalt-induced hypertensive vascular hypertrophy and fibrosis (89). Further studies in DOCA-salt hypertensive mice showed that the recruitment of macrophages in PVAT promotes complement activation, induces perivascular inflammation, and increases the production of TNF- $\alpha$, thereby causing APN downregulation. This is a potential risk factor for hypertension-related vascular inflammation and injury (17), which may be particularly important when considering treatment methods for hypertensionrelated vascular injury. Moreover, in mice with spontaneous hypertension induced by perilipin-1 deletion, PVAT exhibited reduced APN expression, whereas it exhibited enhanced expression of MCP-1, TNF- $\alpha$, and IL-6; additionally, the anticontractile effect of PVAT was lost. These effects were associated with an increased pro-inflammatory response, as well as higher systolic and diastolic blood pressures in aorta (90).

Increased activation of the renin-angiotensin-aldosterone system (RAS) is an important factor in hypertension pathogenesis. With the exception of renin, almost all components of the RAS system are expressed in PVAT, implying key roles in the regulation of hypertension-related perivascular inflammation (72, 129). Lee et al. found that the release of PVAT-derived relaxing factor (PVATRF) from PVAT in spontaneously hypertensive rats was significantly reduced, while the release of Ang II was enhanced (91). In Ang II-induced hypertensive mice, the numbers of leukocytes, T cells, macrophages, and dendritic cells in PVAT were significantly increased $(55,92)$. In those mice, Ang II significantly increased the expression levels of MCP-1, RANTES, and macrophage inflammatory protein $1 \alpha$ (MIP- $1 \alpha$, also known as CCL3) in aorta and PVAT. Furthermore, the activation of angiotensin type 1 receptor (AT1 receptor) in PVAT promotes vascular inflammation and endothelial dysfunction $(93,94)$. Aldosterone may directly promote a pro-inflammatory phenotype in PVAT. Macrophage infiltration and increased C5a expression were detected in adipose tissue from patients with aldosterone-secreting adenoma; these findings were associated with decreased APN expression (17).

Hypertension was more common in obese individuals than in lean individuals. The progress of hypertension is related to the immune response of adipose tissue (130). The antivasoconstrictive properties of healthy PVAT are eliminated in obesity, resulting in increased arterial tension, which is a key mechanism of obesity-related hypertension and vascular dysfunction. Macrophage infiltration in PVAT plays a key role in obesity-related hypertension (95). In mice that were fed a high-fat diet, macrophages accumulated in fat PVAT around the thoracic aorta or mesenteric artery. The absence of class A1 scavenger receptor, a key pattern recognition receptor that regulates macrophage activity, can stimulate the excessive production of vascular endothelial growth factor B in macrophages from PVAT and aorta, increase the accumulation of endothelial lipid in obese mice, and promote obesity-induced elevation of blood pressure (95). Eosinophil-deficient $\Delta$ dblGATA-1 mice reportedly lack the anti-contractile function of PVAT and show elevated blood pressure (96). Notably, Withers et al. demonstrated that obesity is accompanied by a significant decrease in the number of eosinophils present in PVAT, which may lead to a loss of its anti-contractile function (97). This effect was restored by replenishment using purified 
eosinophils in vessels with intact PVAT or by the use of IL-33 to restore the number of eosinophils in PVAT $(96,97)$. These findings suggest that PVAT releases an eosinophil-derived soluble anti-contractile factor. This factor is dependent on B3 adrenoceptor activity and independent of other downstream signaling pathways (e.g., APN and nitric oxide) mediated by immune cells (97). Thus, targeting the number of eosinophils in PVAT may constitute a novel method for the treatment of obesity-related hypertension.

\section{Diabetes Mellitus-Related Vascular Dysfunction}

The progression of DM eventually involves the development of chronic vascular complications and associated cardiovascular diseases; this cardiovascular disease progression is the leading cause of death in diabetic patients worldwide (131). Endothelial dysfunction is the initial vascular defect in DM; it is associated with DM-related macrovascular and microvascular complications (e.g., coronary heart disease, stroke, peripheral vascular disease, diabetic retinopathy, and kidney disease), which represent the main health burden in patients with DM (132). Inflammation is a major pathophysiological process that mediates DM-related endothelial dysfunction. PVAT is presumed to serve as a mechanistic link between T2DM and vascular diseases such as atherosclerosis (133).

In the context of DM, high glucose stimulation induces PVAT transition to a pro-inflammatory (increased CRP, CCL2, and CD36), pro-oxidant, and vasoconstrictive phenotype (98, 99). PVAT inflammation can promote insulin resistance in the vascular system, resulting in impaired insulin-mediated vasodilation and vascular remodeling and subsequent onset of vascular diseases (99). PVAT obtained from obese $\mathrm{db} / \mathrm{db}$ mice greatly impaired insulin-mediated vasodilation of the resistance artery in muscle, while PVAT obtained from nonobese mice promoted vasodilation of this artery (100). Furthermore, obesity and the expansion of PVAT in $\mathrm{db} / \mathrm{db}$ mice cause elimination of insulin-stimulated vasodilation and recovery by blocking inflammation through inhibition of the c-Jun $\mathrm{N}$-terminal kinase pathway, thus indicating a key role for inflammation in PVAT (100).

\section{Abdominal Aortic Aneurysm (AAA)}

Inflammatory cell recruitment to aortic media, macrophage activation, and pro-inflammatory molecule production are important mechanisms involved in AAA (134), which contribute to gradual thinning of the aortic media and adventitia (135). Analysis of samples from human patients has shown that AAAs are surrounded by abundant PVAT (103), and the density of PVAT is higher around the aneurysm sac in patients with aortic aneurysm than in healthy neck tissue, suggesting that the deposition of PVAT is related to AAA pathophysiology (104). Overall, PVAT plays a pro-inflammatory role in the development of AAA.

Genome-wide expression profiling has revealed colocalization of PVAT inflammation with AAA, suggesting that biological changes in PVAT may be functionally associated with AAA pathogenesis (105). Changes in PVAT phenotype and function initiate inflammatory signals, stimulating the recruitment and activation of immune cells; the soluble factors produced by immune cells cause matrix degradation, leading to the initiation and progression of AAA (105). PVAT samples from AAA patients showed increased expression of various proinflammatory genes, including IL-8, protein tyrosine phosphatase receptor type $\mathrm{C}$, lymphocyte-specific protein tyrosine, and CCL5, accompanied by decreased expression of anti-inflammatory genes (e.g., peroxisome proliferator-activated receptor gamma) and increased degradation of extracellular matrix (106). Furthermore, adipose tissue from AAA patients can induce inflammation in healthy VSMCs from control patients, resulting in increased expression of genes involved in aneurysm formation (106). Studies in animal models have shown that PVAT-derived pro-inflammatory factors accelerate the recruitment of macrophages, lymphocytes, and mast cells in the vascular wall (93). Deletion of the AT1a receptor gene in PVAT attenuated AAA development and gelatinolytic activity, as well as the accumulation of macrophages in abdominal aorta and adipose tissue; it also contributed to macrophage polarization from a pro-inflammatory state to an anti-inflammatory state. In addition, obesity-related PVAT dysfunction reportedly promotes Ang II-induced aortic aneurysm formation by secreting plateletderived growth factor-D (PDGF-D). Leukocyte-fibroblast interactions in adventitia enhance the recruitment and activation of local monocytes, leading to aortic aneurysm and aortic dissection $(107,108)$; PDGF-D stimulates the migration and proliferation of adventitial fibroblasts, as well as the expression of pro-inflammatory factors. Notably, adipocytespecific PDGF-D transgenic mice were more likely to form aortic aneurysm after Ang II infusion, accompanied by increased adventitial inflammation and fibrosis (109). Although multiple studies have shown that macrophages are the key inflammatory cells mediating the formation of AAA (110), immunophenotypic analysis of advanced AAA samples infiltrating the largest expansion site demonstrated that $\mathrm{T}$ cells (rather than macrophages) are the main leukocyte subset in AAA; their greatest accumulation occurs in perivascular tissues such as PVAT (111). This discrepancy may be related to differences in AAA stages between studies. However, these findings clearly indicate that inflammation in PVAT and aortic wall contributes to the pathophysiology of AAA; these proposed pathways of inflammatory induction can reveal new therapeutic targets for AAA.

\section{CONCLUSION}

PVAT dysfunction is one of the main risk factors for cardiovascular diseases; PVAT is particularly important because of its close proximity to the vascular wall. Therefore, the importance of PVAT in regulating cardiovascular complications cannot be ignored. Further mechanistic research is needed; however, immune dysfunction (i.e., increased presence of pro-inflammatory mediators, rather than anti-inflammatory mediators) and subsequent chronic inflammation play key roles. Crosstalk between PVAT and vascular system occurs in both 
directions, and it has important roles in vascular homeostasis and disease. In particular, inflammation leads to PVAT dysfunction through inflammatory cells and various proinflammatory factors, thereby exacerbating altered vasodilation, while enhancing vasoconstriction and vascular remodeling; these changes contribute to vascular aging, atherosclerosis, hypertension, and other vascular diseases. In animal and human studies, PVAT dysfunction has been shown to cause various inflammatory vascular diseases, and vascular inflammation is associated with changes in PVAT phenotype; these findings can help to identify vulnerable vascular lesions. Although the mechanism is not entirely clear, the existing evidence shows that PVAT inflammation is a strictly regulated process that occurs in the early stage of vascular disease, which can serve as a valuable target for future treatment. Therefore, further research is needed to explore whether PVAT can be targeted in novel treatments for vascular diseases.

In addition, PVAT-related secretory factors (e.g., adipokines, hormones, and other factors) have important effects on many

\section{REFERENCES}

1. Potente M, Carmeliet P. The Link Between Angiogenesis and Endothelial Metabolism. Annu Rev Physiol (2017) 79:43-66. doi: 10.1146/annurevphysiol-021115-105134

2. Arokiasamy P, Uttamacharya, Kowal P, Capistrant BD, Gildner TE, Thiele E, et al. Chronic Noncommunicable Diseases in 6 Low- and Middle-Income Countries: Findings From Wave 1 of the World Health Organization's Study on Global Ageing and Adult Health (SAGE). Am J Epidemiol (2017) 185 (6):414-28. doi: 10.1093/aje/kww125

3. Gil-Ortega M, Somoza B, Huang Y, Gollasch M, Fernandez-Alfonso MS. Regional Differences in Perivascular Adipose Tissue Impacting Vascular Homeostasis. Trends Endocrinol Metab (2015) 26(7):367-75. doi: 10.1016/ j.tem.2015.04.003

4. Queiroz M, Sena CM. Perivascular Adipose Tissue in Age-Related Vascular Disease. Ageing Res Rev (2020) 59:101040. doi: 10.1016/j.arr.2020.101040

5. Nosalski R, Guzik TJ. Perivascular Adipose Tissue Inflammation in Vascular Disease. Br J Pharmacol (2017) 174(20):3496-513. doi: 10.1111/bph.13705

6. Hu H, Garcia-Barrio M, Jiang ZS, Chen YE, Chang L. Roles of Perivascular Adipose Tissue in Hypertension and Atherosclerosis. Antioxid Redox Signal (2021) 34(9):736-49. doi: 10.1089/ars.2020.8103

7. Han F, Zhang Y, Shao M, Mu Q, Jiao X, Hou N, et al. C1q/TNF-Related Protein 9 Improves the Anti-Contractile Effects of Perivascular Adipose Tissue via the AMPK-eNOS Pathway in Diet-Induced Obese Mice. Clin Exp Pharmacol Physiol (2018) 45(1):50-7. doi: 10.1111/1440-1681.12851

8. Guzik TJ, Mangalat D, Korbut R. Adipocytokines - Novel Link Between Inflammation and Vascular Function? J Physiol Pharmacol (2006) 57 (4):505-28.

9. Guzik TJ, Marvar PJ, Czesnikiewicz-Guzik M, Korbut R. Perivascular Adipose Tissue as a Messenger of the Brain-Vessel Axis: Role in Vascular Inflammation and Dysfunction. J Physiol Pharmacol (2007) 58(4):591-610.

10. Chatterjee TK, Stoll LL, Denning GM, Harrelson A, Blomkalns AL, Idelman G, et al. Proinflammatory Phenotype of Perivascular Adipocytes: Influence of High-Fat Feeding. Circ Res (2009) 104(4):541-9. doi: 10.1161/ CIRCRESAHA.108.182998

11. Landecho MF, Tuero C, Valenti V, Bilbao I, de la Higuera M, Fruhbeck G. Relevance of Leptin and Other Adipokines in Obesity-Associated Cardiovascular Risk. Nutrients (2019) 11(11):2664. doi: 10.3390/ nu11112664

12. Choi HM, Doss HM, Kim KS. Multifaceted Physiological Roles of Adiponectin in Inflammation and Diseases. Int J Mol Sci (2020) 21 (4):1219. doi: 10.3390/ijms21041219

13. Almabrouk TAM, White AD, Ugusman AB, Skiba DS, Katwan OJ, Alganga $\mathrm{H}$, et al. High Fat Diet Attenuates the Anticontractile Activity of Aortic aspects of the vascular system. PVAT dysfunction promotes the dedifferentiation of perivascular adipocytes, such that they no longer serve as lipid storage cells; in contrast, they become metabolically active synthetic tissues, produce pro-inflammatory cytokines and chemokines, and play key roles in cardiovascular disease-related inflammation (5). Overall, extensive analysis of various adipokines is needed to clearly distinguish the physiological and therapeutic effects of these adipokines in the context of vascular dysfunction.

\section{AUTHOR CONTRIBUTIONS}

YL and YZ designed the manuscript and wrote part of it, while YC wrote most of it. ZQ revised and corrected the manuscript, and YW and XL completed the design and drawing of figure and table. All authors contributed to the article and approved the submitted version.

PVAT via a Mechanism Involving AMPK and Reduced Adiponectin Secretion. Front Physiol (2018) 9:51. doi: 10.3389/fphys.2018.00051

14. Han F, Li K, Pan R, Xu W, Han X, Hou N, et al. Calycosin Directly Improves Perivascular Adipose Tissue Dysfunction by Upregulating the Adiponectin/ AMPK/eNOS Pathway in Obese Mice. Food Funct (2018) 9(4):2409-15. doi: 10.1039/C8FO00328A

15. Hou N, Liu Y, Han F, Wang D, Hou X, Hou S, et al. Irisin Improves Perivascular Adipose Tissue Dysfunction via Regulation of the Heme Oxygenase-1/Adiponectin Axis in Diet-Induced Obese Mice. J Mol Cell Cardiol (2016) 99:188-96. doi: 10.1016/j.yjmcc.2016.09.005

16. Han F, Hou N, Liu Y, Huang N, Pan R, Zhang X, et al. Liraglutide Improves Vascular Dysfunction by Regulating a cAMP-Independent PKA-AMPK Pathway in Perivascular Adipose Tissue in Obese Mice. BioMed Pharmacother (2019) 120:109537. doi: 10.1016/j.biopha.2019.109537

17. Ruan CC, Ma Y, Ge Q, Li Y, Zhu LM, Zhang Y, et al. Complement-Mediated Inhibition of Adiponectin Regulates Perivascular Inflammation and Vascular Injury in Hypertension. FASEB J (2017) 31(3):1120-9. doi: 10.1096/fj.201600780R

18. Horimatsu T, Patel AS, Prasad R, Reid LE, Benson TW, Zarzour A, et al Remote Effects of Transplanted Perivascular Adipose Tissue on Endothelial Function and Atherosclerosis. Cardiovasc Drugs Ther (2018) 32(5):503-10. doi: 10.1007/s10557-018-6821-y

19. Badran M, Yassin BA, Lin DTS, Kobor MS, Ayas N, Laher I. Gestational Intermittent Hypoxia Induces Endothelial Dysfunction, Reduces Perivascular Adiponectin and Causes Epigenetic Changes in Adult Male Offspring. J Physiol (2019) 597(22):5349-64. doi: 10.1113/JP277936

20. Hou N, Du G, Han F, Zhang J, Jiao X, Sun X. Irisin Regulates Heme Oxygenase-1/Adiponectin Axis in Perivascular Adipose Tissue and Improves Endothelial Dysfunction in Diet-Induced Obese Mice. Cell Physiol Biochem (2017) 42(2):603-14. doi: 10.1159/000477864

21. Sena CM, Pereira A, Fernandes R, Letra L, Seica RM. Adiponectin Improves Endothelial Function in Mesenteric Arteries of Rats Fed a High-Fat Diet: Role of Perivascular Adipose Tissue. Br J Pharmacol (2017) 174(20):351426. doi: 10.1111/bph.13756

22. Patel VB, Mori J, McLean BA, Basu R, Das SK, Ramprasath T, et al. ACE2 Deficiency Worsens Epicardial Adipose Tissue Inflammation and Cardiac Dysfunction in Response to Diet-Induced Obesity. Diabetes (2016) 65 (1):85-95. doi: 10.2337/db15-1425

23. Zhou Y, Wei Y, Wang L, Wang X, Du X, Sun Z, et al. Decreased Adiponectin and Increased Inflammation Expression in Epicardial Adipose Tissue in Coronary Artery Disease. Cardiovasc Diabetol (2011) 10:2. doi: 10.1186/ 1475-2840-10-2

24. Wang X, Chen Q, Pu H, Wei Q, Duan M, Zhang C, et al. Adiponectin Improves NF-KappaB-Mediated Inflammation and Abates Atherosclerosis 
Progression in Apolipoprotein E-Deficient Mice. Lipids Health Dis (2016) 15:33. doi: 10.1186/s12944-016-0202-y

25. Zhou H, Zhang Z, Qian G, Zhou J. Omentin-1 Attenuates Adipose Tissue Inflammation via Restoration of TXNIP/NLRP3 Signaling in High-Fat DietInduced Obese Mice. Fundam Clin Pharmacol (2020) 34(6):721-35. doi: $10.1111 /$ fcp. 12575

26. Wang J, Gao Y, Lin F, Han K, Wang X. Omentin-1 Attenuates Lipopolysaccharide (LPS)-Induced U937 Macrophages Activation by Inhibiting the TLR4/MyD88/NF-kappaB Signaling. Arch Biochem Biophys (2020) 679:108187. doi: 10.1016/j.abb.2019.108187

27. Zhou Y, Zhang B, Hao C, Huang X, Li X, Huang Y, et al. Omentin-A Novel Adipokine in Respiratory Diseases. Int J Mol Sci (2017) 19(1):73. doi: 10.3390/ijms19010073

28. Leandro A, Queiroz M, Azul L, Seica R, Sena CM. Omentin: A Novel Therapeutic Approach for the Treatment of Endothelial Dysfunction in Type 2 Diabetes. Free Radic Biol Med (2021) 162:233-42. doi: 10.1016/ j.freeradbiomed.2020.10.021

29. Chen Y, Liu F, Han F, Lv L, Tang CE, Xie Z, et al. Omentin-1 Is Associated With Atrial Fibrillation in Patients With Cardiac Valve Disease. BMC Cardiovasc Disord (2020) 20(1):214. doi: 10.1186/s12872-020-01478-1

30. Du Y, Ji Q, Cai L, Huang F, Lai Y, Liu Y, et al. Association Between Omentin-1 Expression in Human Epicardial Adipose Tissue and Coronary Atherosclerosis. Cardiovasc Diabetol (2016) 15:90. doi: 10.1186/s12933-016-0406-5

31. Harada K, Shibata R, Ouchi N, Tokuda Y, Funakubo H, Suzuki M, et al. Increased Expression of the Adipocytokine Omentin in the Epicardial Adipose Tissue of Coronary Artery Disease Patients. Atherosclerosis (2016) 251:299-304. doi: 10.1016/j.atherosclerosis.2016.07.003

32. Fisher FM, Maratos-Flier E. Understanding the Physiology of FGF21. Annu Rev Physiol (2016) 78:223-41. doi: 10.1146/annurev-physiol-021115-105339

33. Wang WF, Li SM, Ren GP, Zheng W, Lu YJ, Yu YH, et al. Recombinant Murine Fibroblast Growth Factor 21 Ameliorates Obesity-Related Inflammation in Monosodium Glutamate-Induced Obesity Rats. Endocrine (2015) 49(1):119-29. doi: 10.1007/s12020-014-0433-5

34. Wang N, Zhao TT, Li SM, Sun X, Li ZC, Li YH, et al. Fibroblast Growth Factor 21 Exerts its Anti-Inflammatory Effects on Multiple Cell Types of Adipose Tissue in Obesity. Obes (Silver Spring) (2019) 27(3):399-408. doi: 10.1002/oby.22376

35. Zhang J, Cheng Y, Gu J, Wang S, Zhou S, Wang Y, et al. Fenofibrate Increases Cardiac Autophagy via FGF21/SIRT1 and Prevents Fibrosis and Inflammation in the Hearts of Type 1 Diabetic Mice. Clin Sci (Lond) (2016) 130(8):625-41. doi: 10.1042/CS20150623

36. Wang N, Li JY, Li S, Guo XC, Wu T, Wang WF, et al. Fibroblast Growth Factor 21 Regulates Foam Cells Formation and Inflammatory Response in Ox-LDL-Induced THP-1 Macrophages. BioMed Pharmacother (2018) 108:1825-34. doi: 10.1016/j.biopha.2018.09.143

37. Yu Y, He J, Li S, Song L, Guo X, Yao W, et al. Fibroblast Growth Factor 21 (FGF21) Inhibits Macrophage-Mediated Inflammation by Activating Nrf2 and Suppressing the NF-kappaB Signaling Pathway. Int Immunopharmacol (2016) 38:144-52. doi: 10.1016/j.intimp.2016.05.026

38. Haberka M, Machnik G, Kowalowka A, Biedron M, Skudrzyk E, RegulskaIlow B, et al. Epicardial, Paracardial, and Perivascular Fat Quantity, Gene Expressions, and Serum Cytokines in Patients With Coronary Artery Disease and Diabetes. Pol Arch Intern Med (2019) 129(11):738-46. doi: 10.20452/pamw.14961

39. Kotulak T, Drapalova J, Kopecky P, Lacinova Z, Kramar P, Riha H, et al. Increased Circulating and Epicardial Adipose Tissue mRNA Expression of Fibroblast Growth Factor-21 After Cardiac Surgery: Possible Role in Postoperative Inflammatory Response and Insulin Resistance. Physiol Res (2011) 60(5):757-67. doi: 10.33549/physiolres. 932134

40. Katsiki N, Mikhailidis DP, Banach M. Leptin, Cardiovascular Diseases and Type 2 Diabetes Mellitus. Acta Pharmacol Sin (2018) 39(7):1176-88. doi: 10.1038/aps.2018.40

41. Gruzdeva O, Borodkina D, Uchasova E, Dyleva Y, Barbarash O. Leptin Resistance: Underlying Mechanisms and Diagnosis. Diabetes Metab Syndr Obes (2019) 12:191-8. doi: 10.2147/DMSO.S182406

42. Lee MW, Lee M, Oh KJ. Adipose Tissue-Derived Signatures for Obesity and Type 2 Diabetes: Adipokines, Batokines and MicroRNAs. J Clin Med (2019) 8(6):854. doi: $10.3390 / \mathrm{jcm} 8060854$
43. Gainsford T, Willson TA, Metcalf D, Handman E, McFarlane C, Ng A, et al. Leptin can Induce Proliferation, Differentiation, and Functional Activation of Hemopoietic Cells. Proc Natl Acad Sci USA (1996) 93(25):14564-8. doi: 10.1073/pnas.93.25.14564

44. Sousa AS, Sponton ACS, Trifone CB, Delbin MA. Aerobic Exercise Training Prevents Perivascular Adipose Tissue-Induced Endothelial Dysfunction in Thoracic Aorta of Obese Mice. Front Physiol (2019) 10:1009. doi: 10.3389/ fphys.2019.01009

45. Mori K, Tsuchiya K, Nakamura S, Miyachi Y, Shiba K, Ogawa Y, et al. Ipragliflozin-Induced Adipose Expansion Inhibits Cuff-Induced Vascular Remodeling in Mice. Cardiovasc Diabetol (2019) 18(1):83. doi: 10.1186/ s12933-019-0886-1

46. Lu D, Wang W, Xia L, Xia P, Yan Y. Gene Expression Profiling Reveals Heterogeneity of Perivascular Adipose Tissues Surrounding Coronary and Internal Thoracic Arteries. Acta Biochim Biophys Sin (Shanghai) (2017) 49 (12):1075-82. doi: 10.1093/abbs/gmx113

47. Drosos I, Chalikias G, Pavlaki M, Kareli D, Epitropou G, Bougioukas G, et al. Differences Between Perivascular Adipose Tissue Surrounding the Heart and the Internal Mammary Artery: Possible Role for the Leptin-InflammationFibrosis-Hypoxia Axis. Clin Res Cardiol (2016) 105(11):887-900. doi: 10.1007/s00392-016-0996-7

48. Moe KT, Naylynn TM, Yin NO, Khairunnisa K, Allen JC, Wong MC, et al. Tumor Necrosis Factor-Alpha Induces Aortic Intima-Media Thickening via Perivascular Adipose Tissue Inflammation. J Vasc Res (2013) 50(3):228-37. doi: $10.1159 / 000350542$

49. Kanda H, Tateya S, Tamori Y, Kotani K, Hiasa K, Kitazawa R, et al. MCP-1 Contributes to Macrophage Infiltration Into Adipose Tissue, Insulin Resistance, and Hepatic Steatosis in Obesity. J Clin Invest (2006) 116 (6):1494-505. doi: 10.1172/JCI26498

50. Chan CT, Moore JP, Budzyn K, Guida E, Diep H, Vinh A, et al. Reversal of Vascular Macrophage Accumulation and Hypertension by a CCR2 Antagonist in Deoxycorticosterone/Salt-Treated Mice. Hypertension (2012) 60(5):1207-12. doi: 10.1161/HYPERTENSIONAHA.112.201251

51. Mateo T, Abu Nabah YN, Abu Taha M, Mata M, Cerda-Nicolas M, Proudfoot AE, et al. Angiotensin II-Induced Mononuclear Leukocyte Interactions With Arteriolar and Venular Endothelium Are Mediated by the Release of Different CC Chemokines. J Immunol (2006) 176(9):5577-86. doi: 10.4049/jimmunol.176.9.5577

52. Krensky AM, Ahn YT. Mechanisms of Disease: Regulation of RANTES (CCL5) in Renal Disease. Nat Clin Pract Nephrol (2007) 3(3):164-70. doi: 10.1038/ncpneph0418

53. Surmi BK, Hasty AH. The Role of Chemokines in Recruitment of Immune Cells to the Artery Wall and Adipose Tissue. Vascul Pharmacol (2010) 52(12):27-36. doi: 10.1016/j.vph.2009.12.004

54. Marques RE, Guabiraba R, Russo RC, Teixeira MM. Targeting CCL5 in Inflammation. Expert Opin Ther Targets (2013) 17(12):1439-60. doi: $10.1517 / 14728222.2013 .837886$

55. Mikolajczyk TP, Nosalski R, Szczepaniak P, Budzyn K, Osmenda G, Skiba D, et al. Role of Chemokine RANTES in the Regulation of Perivascular Inflammation, T-Cell Accumulation, and Vascular Dysfunction in Hypertension. FASEB J (2016) 30(5):1987-99. doi: 10.1096/fj.201500088R

56. Molica F, Morel S, Kwak BR, Rohner-Jeanrenaud F, Steffens S. Adipokines at the Crossroad Between Obesity and Cardiovascular Disease. Thromb Haemost (2015) 113(3):553-66. doi: 10.1160/TH14-06-0513

57. Sun X, Hou N, Han F, Guo Y, Hui Z, Du G, et al. Effect of High Free Fatty Acids on the Anti-Contractile Response of Perivascular Adipose Tissue in Rat Aorta. J Mol Cell Cardiol (2013) 63:169-74. doi: 10.1016/j.yjmcc.2013.07.018

58. Huang N, Mao EW, Hou NN, Liu YP, Han F, Sun XD. Novel Insight Into Perirenal Adipose Tissue: A Neglected Adipose Depot Linking Cardiovascular and Chronic Kidney Disease. World J Diabetes (2020) 11 (4):115-25. doi: 10.4239/wjd.v11.i4.115

59. Gomez-Serrano M, Camafeita E, Lopez JA, Rubio MA, Breton I, GarciaConsuegra I, et al. Differential Proteomic and Oxidative Profiles Unveil Dysfunctional Protein Import to Adipocyte Mitochondria in ObesityAssociated Aging and Diabetes. Redox Biol (2017) 11:415-28. doi: 10.1016/j.redox.2016.12.013

60. Kagota S, Maruyama-Fumoto K, Iwata S, Shimari M, Koyanagi S, Shiokawa $\mathrm{Y}$, et al. Perivascular Adipose Tissue-Enhanced Vasodilation in Metabolic 
Syndrome Rats by Apelin and N-Acetyl(-)L-Cysteine-Sensitive Factor(s). Int J Mol Sci (2018) 20(1):106. doi: 10.3390/ijms20010106

61. Schutz E, Gogiraju R, Pavlaki M, Drosos I, Georgiadis GS, Argyriou C, et al. Age-Dependent and -Independent Effects of Perivascular Adipose Tissue and Its Paracrine Activities During Neointima Formation. Int J Mol Sci (2019) 21(1):282. doi: 10.3390/ijms21010282

62. Pan XX, Ruan CC, Liu XY, Kong LR, Ma Y, Wu QH, et al. Perivascular Adipose Tissue-Derived Stromal Cells Contribute to Vascular Remodeling During Aging. Aging Cell (2019) 18(4):e12969. doi: 10.1111/acel.12969

63. Agabiti-Rosei C, Favero G, De Ciuceis C, Rossini C, Porteri E, Rodella LF, et al. Effect of Long-Term Treatment With Melatonin on Vascular Markers of Oxidative Stress/Inflammation and on the Anticontractile Activity of Perivascular Fat in Aging Mice. Hypertens Res (2017) 40(1):41-50. doi: 10.1038/hr.2016.103

64. Chang L, Zhao X, Garcia-Barrio M, Zhang J, Eugene Chen Y. MitoNEET in Perivascular Adipose Tissue Prevents Arterial Stiffness in Aging Mice. Cardiovasc Drugs Ther (2018) 32(5):531-9. doi: 10.1007/s10557-018-6809-7

65. Bailey-Downs LC, Tucsek Z, Toth P, Sosnowska D, Gautam T, Sonntag WE, et al. Aging Exacerbates Obesity-Induced Oxidative Stress and Inflammation in Perivascular Adipose Tissue in Mice: A Paracrine Mechanism Contributing to Vascular Redox Dysregulation and Inflammation. J Gerontol A Biol Sci Med Sci (2013) 68(7):780-92. doi: 10.1093/gerona/ gls238

66. Barandier C, Montani JP, Yang Z. Mature Adipocytes and Perivascular Adipose Tissue Stimulate Vascular Smooth Muscle Cell Proliferation: Effects of Aging and Obesity. Am J Physiol Heart Circ Physiol (2005) 289(5):H180713. doi: 10.1152 /ajpheart.01259.2004

67. Farias-Itao DS, Pasqualucci CA, Nishizawa A, da Silva LFF, Campos FM, Bittencourt MS, et al. B Lymphocytes and Macrophages in the Perivascular Adipose Tissue Are Associated With Coronary Atherosclerosis: An Autopsy Study. J Am Heart Assoc (2019) 8(24):e013793. doi: 10.1161/JAHA. 119.013793

68. Nosalski R, Mikolajczyk T, Siedlinski M, Saju B, Koziol J, Maffia P, et al. Nox1/4 Inhibition Exacerbates Age Dependent Perivascular Inflammation and Fibrosis in a Model of Spontaneous Hypertension. Pharmacol Res (2020) 161:105235. doi: 10.1016/j.phrs.2020.105235

69. Srikakulapu P, Upadhye A, Drago F, Perry HM, Bontha SV, McSkimming C, et al. Chemokine Receptor-6 Promotes B-1 Cell Trafficking to Perivascular Adipose Tissue, Local IgM Production and Atheroprotection. Front Immunol (2021) 12:636013. doi: 10.3389/fimmu.2021.636013

70. Tomono Y, Iwai M, Inaba S, Mogi M, Horiuchi M. Blockade of AT1 Receptor Improves Adipocyte Differentiation in Atherosclerotic and Diabetic Models. Am J Hypertens (2008) 21(2):206-12. doi: 10.1038/ ajh.2007.50

71. Iwai M, Tomono Y, Inaba S, Kanno H, Senba I, Mogi M, et al. AT2 Receptor Deficiency Attenuates Adipocyte Differentiation and Decreases Adipocyte Number in Atherosclerotic Mice. Am J Hypertens (2009) 22(7):784-91. doi: 10.1038/ajh.2009.85

72. Galvez-Prieto B, Bolbrinker J, Stucchi P, de Las Heras AI, Merino B, Arribas $\mathrm{S}$, et al. Comparative Expression Analysis of the Renin-Angiotensin System Components Between White and Brown Perivascular Adipose Tissue. $J$ Endocrinol (2008) 197(1):55-64. doi: 10.1677/JOE-07-0284

73. Chang L, Villacorta L, Li R, Hamblin M, Xu W, Dou C, et al. Loss of Perivascular Adipose Tissue on Peroxisome Proliferator-Activated Receptor-Gamma Deletion in Smooth Muscle Cells Impairs Intravascular Thermoregulation and Enhances Atherosclerosis. Circulation (2012) 126 (9):1067-78. doi: 10.1161/CIRCULATIONAHA.112.104489

74. Skiba DS, Nosalski R, Mikolajczyk TP, Siedlinski M, Rios FJ, Montezano AC, et al. Anti-Atherosclerotic Effect of the Angiotensin 1-7 Mimetic AVE0991 Is Mediated by Inhibition of Perivascular and Plaque Inflammation in Early Atherosclerosis. Br J Pharmacol (2017) 174(22):4055-69. doi: 10.1111/ bph. 13685

75. Moos MP, John N, Grabner R, Nossmann S, Gunther B, Vollandt R, et al. The Lamina Adventitia Is the Major Site of Immune Cell Accumulation in Standard Chow-Fed Apolipoprotein E-Deficient Mice. Arterioscler Thromb Vasc Biol (2005) 25(11):2386-91. doi: 10.1161/01.ATV.0000187470.31662.fe

76. Galkina E, Kadl A, Sanders J, Varughese D, Sarembock IJ, Ley K. Lymphocyte Recruitment Into the Aortic Wall Before and During
Development of Atherosclerosis is Partially L-Selectin Dependent. $J$ Exp Med (2006) 203(5):1273-82. doi: 10.1084/jem.20052205

77. Ohman MK, Luo W, Wang H, Guo C, Abdallah W, Russo HM, et al. Perivascular Visceral Adipose Tissue Induces Atherosclerosis in Apolipoprotein E Deficient Mice. Atherosclerosis (2011) 219(1):33-9. doi: 10.1016/j.atherosclerosis.2011.07.012

78. Tavora F, Kutys R, Li L, Ripple M, Fowler D, Burke A. Adventitial Lymphocytic Inflammation in Human Coronary Arteries With Intimal Atherosclerosis. Cardiovasc Pathol (2010) 19(3):e61-8. doi: 10.1016/ j.carpath.2009.02.001

79. Verhagen SN, Vink A, van der Graaf Y, Visseren FL. Coronary Perivascular Adipose Tissue Characteristics Are Related to Atherosclerotic Plaque Size and Composition. A Post-Mortem Study. Atherosclerosis (2012) 225(1):99104. doi: 10.1016/j.atherosclerosis.2012.08.031

80. Kralova Lesna I, Tonar Z, Malek I, Maluskova J, Nedorost L, Pirk J, et al. Is the Amount of Coronary Perivascular Fat Related to Atherosclerosis? Physiol Res (2015) 64(Suppl 3):S435-43. doi: 10.33549/physiolres.933151

81. Mazzotta C, Basu S, Gower AC, Karki S, Farb MG, Sroczynski E, et al. Perivascular Adipose Tissue Inflammation in Ischemic Heart Disease. Arterioscler Thromb Vasc Biol (2021) 41(3):1239-50. doi: 10.1161/ ATVBAHA.120.315865

82. Baker AR, Silva NF, Quinn DW, Harte AL, Pagano D, Bonser RS, et al. Human Epicardial Adipose Tissue Expresses a Pathogenic Profile of Adipocytokines in Patients With Cardiovascular Disease. Cardiovasc Diabetol (2006) 5:1. doi: 10.1186/1475-2840-5-1

83. Iacobellis G, Pistilli D, Gucciardo M, Leonetti F, Miraldi F, Brancaccio G, et al. Adiponectin Expression in Human Epicardial Adipose Tissue In Vivo Is Lower in Patients With Coronary Artery Disease. Cytokine (2005) 29 (6):251-5. doi: 10.1016/j.cyto.2004.11.002

84. Mazurek T, Zhang L, Zalewski A, Mannion JD, Diehl JT, Arafat H, et al. Human Epicardial Adipose Tissue Is a Source of Inflammatory Mediators. Circulation (2003) 108(20):2460-6. doi: 10.1161/01.CIR.0000099542.57313.C5

85. Langheim S, Dreas L, Veschini L, Maisano F, Foglieni C, Ferrarello S, et al. Increased Expression and Secretion of Resistin in Epicardial Adipose Tissue of Patients With Acute Coronary Syndrome. Am J Physiol Heart Circ Physiol (2010) 298(3):H746-53. doi: 10.1152/ajpheart.00617.2009

86. Antonopoulos AS, Sanna F, Sabharwal N, Thomas S, Oikonomou EK, Herdman L, et al. Detecting Human Coronary Inflammation by Imaging Perivascular Fat. Sci Transl Med (2017) 9(398):eaal2658. doi: 10.1126/ scitranslmed.aal2658

87. Kossmann S, Schwenk M, Hausding M, Karbach SH, Schmidgen MI, Brandt $\mathrm{M}$, et al. Angiotensin II-Induced Vascular Dysfunction Depends on Interferon-Gamma-Driven Immune Cell Recruitment and Mutual Activation of Monocytes and NK-Cells. Arterioscler Thromb Vasc Biol (2013) 33(6):1313-9. doi: 10.1161/ATVBAHA.113.301437

88. Ruan CC, Zhu DL, Chen QZ, Chen J, Guo SJ, Li XD, et al. Perivascular Adipose Tissue-Derived Complement 3 Is Required for Adventitial Fibroblast Functions and Adventitial Remodeling in Deoxycorticosterone Acetate-Salt Hypertensive Rats. Arterioscler Thromb Vasc Biol (2010) 30 (12):2568-74. doi: 10.1161/ATVBAHA.110.215525

89. Ruan CC, Ge Q, Li Y, Li XD, Chen DR, Ji KD, et al. Complement-Mediated Macrophage Polarization in Perivascular Adipose Tissue Contributes to Vascular Injury in Deoxycorticosterone Acetate-Salt Mice. Arterioscler Thromb Vasc Biol (2015) 35(3):598-606. doi: 10.1161/ATVBAHA. 114.304927

90. Zou L, Wang W, Liu S, Zhao X, Lyv Y, Du C, et al. Spontaneous Hypertension Occurs With Adipose Tissue Dysfunction in Perilipin-1 Null Mice. Biochim Biophys Acta (2016) 1862(2):182-91. doi: 10.1016/ j.bbadis.2015.10.024

91. Lee YC, Chang HH, Chiang CL, Liu CH, Yeh JI, Chen MF, et al. Role of Perivascular Adipose Tissue-Derived Methyl Palmitate in Vascular Tone Regulation and Pathogenesis of Hypertension. Circulation (2011) 124 (10):1160-71. doi: 10.1161/CIRCULATIONAHA.111.027375

92. Mikolajczyk TP, Nosalski R, Skiba DS, Koziol J, Mazur M, Justo-Junior AS, et al. 1,2,3,4,6-Penta-O-Galloyl-Beta-D-Glucose Modulates Perivascular Inflammation and Prevents Vascular Dysfunction in Angiotensin IIInduced Hypertension. Br J Pharmacol (2019) 176(12):1951-65. doi: 10.1111/bph.14583 
93. Sakaue T, Suzuki J, Hamaguchi M, Suehiro C, Tanino A, Nagao T, et al. Perivascular Adipose Tissue Angiotensin II Type 1 Receptor Promotes Vascular Inflammation and Aneurysm Formation. Hypertension (2017) 70 (4):780-9. doi: 10.1161/HYPERTENSIONAHA.117.09512

94. Kagota S, Maruyama-Fumoto K, Shimari M, McGuire JJ, Shinozuka K. Angiotensin II Type 1 Receptor Antagonist Azilsartan Restores Vascular Reactivity Through a Perivascular Adipose Tissue-Independent Mechanism in Rats With Metabolic Syndrome. Cardiovasc Drugs Ther (2019) 33(5):5019. doi: 10.1007/s10557-019-06900-1

95. Zhu X, Wang Y, Zhu L, Zhu Y, Zhang K, Wang L, et al. Class A1 Scavenger Receptor Prevents Obesity-Associated Blood Pressure Elevation Through Suppressing Overproduction of Vascular Endothelial Growth Factor B in Macrophages. Cardiovasc Res (2021) 117(2):547-60. doi: 10.1093/cvr/ craa030

96. Saxton SN, Whitley AS, Potter RJ, Withers SB, Grencis R, Heagerty AM. Interleukin-33 Rescues Perivascular Adipose Tissue Anticontractile Function in Obesity. Am J Physiol Heart Circ Physiol (2020) 319(6): H1387-H97. doi: 10.1152/ajpheart.00491.2020

97. Withers SB, Forman R, Meza-Perez S, Sorobetea D, Sitnik K, Hopwood T, et al. Eosinophils Are Key Regulators of Perivascular Adipose Tissue and Vascular Functionality. Sci Rep (2017) 7:44571. doi: 10.1038/srep44571

98. Azul L, Leandro A, Boroumand P, Klip A, Seica R, Sena CM. Increased Inflammation, Oxidative Stress and a Reduction in Antioxidant Defense Enzymes in Perivascular Adipose Tissue Contribute to Vascular Dysfunction in Type 2 Diabetes. Free Radic Biol Med (2020) 146:264-74. doi: 10.1016/ j.freeradbiomed.2019.11.002

99. Ganbaatar B, Fukuda D, Shinohara M, Yagi S, Kusunose K, Yamada H, et al. Empagliflozin Ameliorates Endothelial Dysfunction and Suppresses Atherogenesis in Diabetic Apolipoprotein E-Deficient Mice. Eur J Pharmacol (2020) 875:173040. doi: 10.1016/j.jphar.2020.173040

100. Meijer RI, Bakker W, Alta CL, Sipkema P, Yudkin JS, Viollet B, et al. Perivascular Adipose Tissue Control of Insulin-Induced Vasoreactivity in Muscle Is Impaired in Db/Db Mice. Diabetes (2013) 62(2):590-8. doi: 10.2337/db11-1603

101. Qiu T, Li M, Tanner MA, Yang Y, Sowers JR, Korthuis RJ, et al. Depletion of Dendritic Cells in Perivascular Adipose Tissue Improves Arterial Relaxation Responses in Type 2 Diabetic Mice. Metabolism (2018) 85:76-89. doi: 10.1016/j.metabol.2018.03.002

102. Wang J, Polaki V, Chen S, Bihl JC. Exercise Improves Endothelial Function Associated With Alleviated Inflammation and Oxidative Stress of Perivascular Adipose Tissue in Type 2 Diabetic Mice. Oxid Med Cell Longev (2020) 2020:8830537. doi: 10.1155/2020/8830537

103. Folkesson M, Vorkapic E, Gulbins E, Japtok L, Kleuser B, Welander M, et al. Inflammatory Cells, Ceramides, and Expression of Proteases in Perivascular Adipose Tissue Adjacent to Human Abdominal Aortic Aneurysms. J Vasc Surg (2017) 65(4):1171-9 e1. doi: 10.1016/j.jvs.2015.12.056

104. Dias-Neto M, Meekel JP, van Schaik TG, Hoozemans J, Sousa-Nunes F, Henriques-Coelho T, et al. High Density of Periaortic Adipose Tissue in Abdominal Aortic Aneurysm. Eur J Vasc Endovasc Surg (2018) 56(5):66371. doi: 10.1016/j.ejvs.2018.07.008

105. Piacentini L, Werba JP, Bono E, Saccu C, Tremoli E, Spirito R, et al. GenomeWide Expression Profiling Unveils Autoimmune Response Signatures in the Perivascular Adipose Tissue of Abdominal Aortic Aneurysm. Arterioscler Thromb Vasc Biol (2019) 39(2):237-49. doi: 10.1161/ATVBAHA.118.311803

106. Meekel JP, Dias-Neto M, Bogunovic N, Conceicao G, Sousa-Mendes C, Stoll GR, et al. Inflammatory Gene Expression of Human Perivascular Adipose Tissue in Abdominal Aortic Aneurysms. Eur J Vasc Endovasc Surg (2021) 61 (6):1008-16. doi: 10.1016/j.jvssci.2020.11.011

107. Tieu BC, Lee C, Sun H, Lejeune W, Recinos A 3rd, Ju X, et al. An Adventitial IL-6/MCP1 Amplification Loop Accelerates Macrophage-Mediated Vascular Inflammation Leading to Aortic Dissection in Mice. J Clin Invest (2009) 119 (12):3637-51. doi: 10.1172/JCI38308

108. Anzai A, Shimoda M, Endo J, Kohno T, Katsumata Y, Matsuhashi T, et al. Adventitial Cxcl1/G-CSF Expression in Response to Acute Aortic Dissection Triggers Local Neutrophil Recruitment and Activation Leading to Aortic Rupture. Circ Res (2015) 116(4):612-23. doi: 10.1161/CIRCRESAHA.116.304918

109. Zhang ZB, Ruan CC, Lin JR, Xu L, Chen XH, Du YN, et al. Perivascular Adipose Tissue-Derived PDGF-D Contributes to Aortic Aneurysm
Formation During Obesity. Diabetes (2018) 67(8):1549-60. doi: 10.2337/ db18-0098

110. Blomkalns AL, Gavrila D, Thomas M, Neltner BS, Blanco VM, Benjamin SB, et al. CD14 Directs Adventitial Macrophage Precursor Recruitment: Role in Early Abdominal Aortic Aneurysm Formation. J Am Heart Assoc (2013) 2 (2):e000065. doi: 10.1161/JAHA.112.000065

111. Sagan A, Mikolajczyk TP, Mrowiecki W, MacRitchie N, Daly K, Meldrum A, et al. T Cells Are Dominant Population in Human Abdominal Aortic Aneurysms and Their Infiltration in the Perivascular Tissue Correlates With Disease Severity. Front Immunol (2019) 10:1979. doi: 10.3389/ fimmu.2019.01979

112. Paneni F, Diaz Cañestro C, Libby P, Lüscher TF, Camici GG. The Aging Cardiovascular System: Understanding It at the Cellular and Clinical Levels. J Am Coll Cardiol (2017) 69(15):1952-67. doi: 10.1016/j.jacc.2017.01.064

113. Liu Y, Du X, Huang Z, Zheng Y, Quan N. Sestrin 2 Controls the Cardiovascular Aging Process via an Integrated Network of Signaling Pathways. Ageing Res Rev (2020) 62:101096. doi: 10.1016/j.arr.2020.101096

114. Sun W, Wang Y, Zheng Y, Quan N. The Emerging Role of Sestrin2 in Cell Metabolism, and Cardiovascular and Age-Related Diseases. Aging Dis (2020) 11(1):154-63. doi: 10.14336/AD.2019.0320

115. Ungvari Z, Tarantini S, Donato AJ, Galvan V, Csiszar A. Mechanisms of Vascular Aging. Circ Res (2018) 123(7):849-67. doi: 10.1161/ CIRCRESAHA.118.311378

116. Butterfield DA, Poon HF. The Senescence-Accelerated Prone Mouse (SAMP8): A Model of Age-Related Cognitive Decline With Relevance to Alterations of the Gene Expression and Protein Abnormalities in Alzheimer's Disease. Exp Gerontol (2005) 40(10):774-83. doi: 10.1016/ j.exger.2005.05.007

117. Libby P. Inflammation in Atherosclerosis. Arterioscler Thromb Vasc Biol (2012) 32(9):2045-51. doi: 10.1161/ATVBAHA.108.179705

118. Ahmadieh S, Kim HW, Weintraub NL. Potential Role of Perivascular Adipose Tissue in Modulating Atherosclerosis. Clin Sci (Lond) (2020) 134 (1):3-13. doi: 10.1042/CS20190577

119. Xiong W, Zhao X, Villacorta L, Rom O, Garcia-Barrio MT, Guo Y, et al. Brown Adipocyte-Specific PPARgamma (Peroxisome Proliferator-Activated Receptor Gamma) Deletion Impairs Perivascular Adipose Tissue Development and Enhances Atherosclerosis in Mice. Arterioscler Thromb Vasc Biol (2018) 38(8):1738-47. doi: 10.1161/ATVBAHA.118.311367

120. Srikakulapu P, Upadhye A, Rosenfeld SM, Marshall MA, McSkimming C, Hickman AW, et al. Perivascular Adipose Tissue Harbors Atheroprotective IgM-Producing B Cells. Front Physiol (2017) 8:719. doi: 10.3389/ fphys.2017.00719

121. Terada K, Yamada H, Kikai M, Wakana N, Yamamoto K, Wada N, et al. Transplantation of Periaortic Adipose Tissue Inhibits Atherosclerosis in Apoe(-/-) Mice by Evoking TGF-Beta1-Mediated Anti-Inflammatory Response in Transplanted Graft. Biochem Biophys Res Commun (2018) 501(1):145-51. doi: 10.1016/j.bbrc.2018.04.196

122. Li C, Wang Z, Wang C, Ma Q, Zhao Y. Perivascular Adipose Tissue-Derived Adiponectin Inhibits Collar-Induced Carotid Atherosclerosis by Promoting Macrophage Autophagy. PloS One (2015) 10(5):e0124031. doi: 10.1371/ journal.pone. 0124031

123. Henrichot E, Juge-Aubry CE, Pernin A, Pache JC, Velebit V, Dayer JM, et al. Production of Chemokines by Perivascular Adipose Tissue: A Role in the Pathogenesis of Atherosclerosis? Arterioscler Thromb Vasc Biol (2005) 25 (12):2594-9. doi: 10.1161/01.ATV.0000188508.40052.35

124. Chatterjee TK, Aronow BJ, Tong WS, Manka D, Tang Y, Bogdanov VY, et al. Human Coronary Artery Perivascular Adipocytes Overexpress Genes Responsible for Regulating Vascular Morphology, Inflammation, and Hemostasis. Physiol Genomics (2013) 45(16):697-709. doi: 10.1152/ physiolgenomics.00042.2013

125. McMaster WG, Kirabo A, Madhur MS, Harrison DG. Inflammation, Immunity, and Hypertensive End-Organ Damage. Circ Res (2015) 116 (6):1022-33. doi: 10.1161/CIRCRESAHA.116.303697

126. Xiao L, Harrison DG. Inflammation in Hypertension. Can J Cardiol (2020) 36(5):635-47. doi: 10.1016/j.cjca.2020.01.013

127. Harrison DG, Guzik TJ, Lob HE, Madhur MS, Marvar PJ, Thabet SR, et al. Inflammation, Immunity, and Hypertension. Hypertension (2011) 57 (2):132-40. doi: 10.1161/HYPERTENSIONAHA.110.163576 
128. Oriowo MA. Perivascular Adipose Tissue, Vascular Reactivity and Hypertension. Med Princ Pract (2015) 24(Suppl 1):29-37. doi: 10.1159/000356380

129. Nguyen Dinh Cat A, Touyz RM. A New Look at the Renin-Angiotensin System-Focusing on the Vascular System. Peptides (2011) 32(10):2141-50. doi: 10.1016/j.peptides.2011.09.010

130. DeMarco VG, Aroor AR, Sowers JR. The Pathophysiology of Hypertension in Patients With Obesity. Nat Rev Endocrinol (2014) 10(6):364-76. doi: 10.1038/nrendo.2014.44

131. Naveed A, Farrukh L, Sana MK, Naveed B, Randhawa FA. Pharmacological Primary Prevention of Diabetes Mellitus Type II: A Narrative Review. Cureus (2020) 12(8):e10033. doi: 10.7759/cureus.10033

132. Einarson TR, Acs A, Ludwig C, Panton UH. Prevalence of Cardiovascular Disease in Type 2 Diabetes: A Systematic Literature Review of Scientific Evidence From Across the World in 2007-2017. Cardiovasc Diabetol (2018) 17(1):83. doi: 10.1186/s12933-018-0728-6

133. Calabro P, Yeh ET. Obesity, Inflammation, and Vascular Disease: The Role of the Adipose Tissue as an Endocrine Organ. Subcell Biochem (2007) 42:6391. doi: 10.1007/1-4020-5688-5_3

134. Hellenthal FA, Buurman WA, Wodzig WK, Schurink GW. Biomarkers of Abdominal Aortic Aneurysm Progression. Part 2: Inflammation. Nat Rev Cardiol (2009) 6(8):543-52. doi: 10.1038/nrcardio.2009.102
135. Gurung R, Choong AM, Woo CC, Foo R, Sorokin V. Genetic and Epigenetic Mechanisms Underlying Vascular Smooth Muscle Cell Phenotypic Modulation in Abdominal Aortic Aneurysm. Int J Mol Sci (2020) 21 (17):6334. doi: 10.3390/ijms21176334

Conflict of Interest: The authors declare that the research was conducted in the absence of any commercial or financial relationships that could be construed as a potential conflict of interest.

Publisher's Note: All claims expressed in this article are solely those of the authors and do not necessarily represent those of their affiliated organizations, or those of the publisher, the editors and the reviewers. Any product that may be evaluated in this article, or claim that may be made by its manufacturer, is not guaranteed or endorsed by the publisher.

Copyright (C) 2021 Chen, Qin, Wang, Li, Zheng and Liu. This is an open-access article distributed under the terms of the Creative Commons Attribution License (CC BY). The use, distribution or reproduction in other forums is permitted, provided the original author(s) and the copyright owner(s) are credited and that the original publication in this journal is cited, in accordance with accepted academic practice. No use, distribution or reproduction is permitted which does not comply with these terms. 